\title{
Muhasebe Meslek Mensuplarının Proaktif Kişilik Özelliklerinin, Kariyer Memnuniyeti İle UFRS’ ye Bakış Açıları ve Bilgi Düzeyleri Üzerine Etkisi
}

\author{
Ender BOYAR* \\ Ali Haydar GÜNGÖRMÜŞ**
}

\section{ÖZET}

Bu çalışmanın amacı, muhasebe meslek mensuplarının proaktif kişilik özelliklerinin UFRS' ye bakış açılarına ve bilgi düzeylerine etkisini, kariyer memnuniyeti üzerinden ölçmektir. Proaktif kişilik yapısına sahip bireyler, iş hayatındaki hedeflere ulaşmak için sürekli kendilerini geliştirir ve bu yönde caba içinde olurlar. Kariyerlerinden memnun olan meslek mensuplarının, mesleki gelişmeleri yakından takip etmeleri ve değişime olumlu bakmaları beklenir. Yapılan araştırma sonucunda, proaktif kişilik yapısına sahip olan muhasebe meslek mensuplarının, kariyerlerinden memnun olduklarl, kariyer memnuniyeti yüksek olan muhasebe meslek mensuplarının UFRS değerleme ölçülerini bilme düzeylerinin yüksek olduğu tespit edilmiştir.

Anahtar Kelimeler: Proaktif Kişilik, UFRS, Kariyer Memnuniyeti, Muhasebe Meslek Mensubu, Mesleki Bilgi

JEL Sinıflandırması: M12, M41

The Effect of Proactive Personality of CPAs on Career Satisfaction, IFRS Perception And Knowledge Level

\section{ABSTRACT}

The purpose of this study is to test effect of proactive personality of CPAs on career satisfaction, IFRS perception and knowledge level. In order to achieve their goals in work life, individuals with proactive personality improve themselves continuously and are always in struggle for the improvement. Satisfied members of the profession are expected to follow their professional development closely and perceive improvement positively. As a result of the study, it has been discovered that the accounting members with proactive personality are happy with their career, and has been identified that those highly satisfied members are fully aware of the knowledge of IFRS and have high awareness of valuation measures.

Keywords: Proactive personality, IFRS, Career success, CPA, Professional knowledge. Jel Classification: M12, M41

\footnotetext{
*Yrd. Doç. Dr. Ender Boyar, Fatih Üniversitesi, İşletme Bölümü, Öğretim Üyesi, enderboyar@fatih.edu.tr

** Yrd. Doç. Dr. Ali Haydar Güngörmüş, Fatih Üniversitesi, İşletme Yönetimi Programı, Öğretim Üyesi, ahgungor@fatih.edu.tr
} 


\section{GİRIŞ}

Uluslararası muhasebe standartlarına uyumlaştırma sürecinin kurumsal boyutu olduğu kadar, daha çok muhasebe meslek mensuplarını ilgilendiren bireysel boyutu da bulunmaktadır. Uluslararası muhasebe standartlarına geçiş sürecini etkiyen birçok bireysel faktör söz konusudur. Çalışmamızda, öznel kariyer memnuniyetinin ve proaktif kişilik özelliklerinin, Uluslararası muhasebe standartlarına bakış açısı ve bilgi düzeyi üzerine olan etkisi incelenmiştir.

Proaktif kişilik, çevresinde değişime neden olacak bir etki oluşturma amacıyla harekete geçen kişilik özelliğine sahip insanları belirtir. Proaktif kişiliğe sahip bireyler, kendilerine firsatlar açmaya çalı̧̧ılar ve açtıkları bu firsatlar üzerinden girişimde bulunurlar ve anlamlı bir fark oluşturuncaya kadar sabır gösterirler. Yüksek standartlar oluşturma eğilimlidirler ve bu standartlara ulaşmak için tüm kaynaklara sahiptirler. Proaktif kişilik, kişilerin bir değişimi başlatma ve çevreyi etkilemeleri gibi aktif rol üstlenmelerine değinmektedir. Bu kişilik özelliğine sahip bireylerin davranışlarını ayıran ana özellik, işe karşı pasif olmak yerine, aktif bir yaklaşım içinde olmalarıdır (Bateman ve Crant, 1993).

Kariyer memnuniyetini etkileyen faktörler üzerine yapılan çalışmalar daha çok örgütsel düzeyde ele alınmıştır. Kariyer memnuniyetine yönelik olarak yapılan çalışmalarda oluşturulan kapsamlı modellere, bir dizi bireysel ve örgütsel değiş̧enler de dahil edilmiştir (Judge ve Bretz, 1994; Judge, Cable, Boudreau ve Bretz, 1995; Wayne, Liden, Kraimer ve Graf, 1999; Seibert, Crant ve Kraimer, 1999). Bu çalışmalarda, bireysel düzeyde, demografik, beşeri ve motivasyon değişkenlerinin, kariyer memnuniyeti üzerinde etkisi olduğu tespit edilmiştir. Benzer şekilde örgütsel düzeyde de firma büyüklüğü, endüstri sektörü ve coğrafi konumu gibi değişkenlerin de kariyer memnuniyeti üzerinde etkileri gözlenmiştir.

Bireysel düzeyde kişilik özelliklerinin kariyer memnuniyeti üzerine etkisi üzerine de çalışmalar yapılmıştır (Seibert, Crant ve Kraimer, 1999). Bu çalışmada proaktif kişilik özelliklerinin öznel kariyer memnuniyeti üzerine olumlu etkileri olduğu tespit edilmiştir (Judge vd., 1995).

2013 yılı başından itibaren yürürlüğe giren yeni Türk Ticaret Kanunu ile birlikte 2000' li yıllardan itibaren başlamış olan UFRS yakınsama çalışmaları hızlanmıştır. Bu konu akademik alanda da ilgi görmüş ve muhasebe meslek mensuplarının UFRS' ye bakış açısına yönelik olarak çeşitli çalışmalar yapılmıştır (Uyar ve Güngörmüş, 2013; Hatunoğlu vd., 2013; Ağca ve Dalkılıç, 2014; Bengü vd., 2014).

Çalışmamızda Seibert, Crant ve Kraimer' in (1999) yapmış olduğu proaktif kişiliğin kariyer memnuniyeti üzerine olan genel etkisi, özelde muhasebe meslek mensupları üzerine uygulanmıştır. $\mathrm{Bu}$ çalışma genişletilerek, muhasebe meslek mensuplarının kariyer memnuniyetlerinin, UFRS’ ye bakış açısı ve bilgi düzeyi üzerine olan etkisi araştırılmıştır. 


\section{KAVRAMSAL ÇERÇEVE VE HIPOTEZLER}

İnsanlar, içinde bulundukları sosyal ortamlarla etkileşim halindedirler. Araştırmalar, kişisel özellikleri farklı bazı bireylerin çevrelerini daha fazla etkilemeye yatkın olduğunu ortaya koymuştur (Bateman ve Crant, 1993). Bateman ve Crant' a göre, mevcut durumdan bağımsız olarak çevresinde değişim etkisi yapan kişiler, prokatif kişilik yapısına sahiptirler. Proaktif insanlar, fırsatlarla karşılaştıklarında onları değerlendirir, inisiyatif alır ve anlamlı bir değişim oluşturuncaya kadar kararlı hareket ederler. Yapılan çalışmalarda proaktif kişilik özelliğinin bazı davranışsal sonuçları olduğu da ortaya konmuştur (Bateman ve Crant, 1993; Crant,1995)

Kariyer memnuniyeti açısından, kişinin iş ortamını etkilemeye çalışması bir dizi avantaj sunmaktadır. İş ortamında kontrolü elinde bulunduranların, çevresel yükümlülükleri anlamaları ve değişimleri sezmeleri daha olasıdır (Bell ve Staw, 1989). Proaktif kişilerin iş hayatlarına ve kariyerlerine bakışları, proaktif olmayanlardan daha farklıdır (Seibert, Crant ve Kraimer, 1999). Bu kişilerin kariyer yönetim faaliyetlerinde daha aktif ve 1srarcı olmaları, kariyer desteği bulmaları daha olasıdır. Beklenmedik çevresel faktörleri tahmin edip ve yapıcı etkide bulunabilirler (Ashford ve Black, 1996; Frese vd, 1997, Seibert, Crant ve Kraimer, 1999).

Bu durumda;

1. Hipotez: Proaktif kişilik ile Kariyer memnuniyeti arasında pozitif yönlü ilişki vardır.

Muhasebe dünyasında UFRS' ye yakınsama ve uyumlaştırma çalışmaları oldukça ilerlemiştir. Küresel anlamda bu konuda en önemli rolü IASB yüklenmiştir (Larson ve Street, 2004). Gelişmekte olan ülkeler, UFRS' ye uyum sağlamak için çaba harcamaktadırlar. UFRS' ye uyumun kültürel boyutları (Karabınar, 2005) olduğu gibi, bireysel boyutları da olduğu açıktır. Uyum sağlamanın, çeşitli engelleri ve zorlukları da vardır. Personelin eğitimi, yazılım sistemlerinin değişimi, çeviri sorunları, danışmanlık hizmetleri ve bunların maliyetleri gibi birçok sorun mevcuttur (Tyrall vd., 2007). Uyum konusunda katılımcıların çok istekli olmadığı bazı çalışmalarla ortaya konmuştur (Jones ve Higgins, 2006; Ballas vd., 2010; Uyar ve Güngörmüş, 2013). Kariyerlerinden memnun olan meslek mensuplarının, mesleki gelişmeleri yakından takip etmeleri ve değişime olumlu bakmaları beklenir.

Bu durumda;

2. Hipotez: Kariyer memnuniyeti ile UFRS’ ye olumlu bakış açısı arasında pozitif yönlü ilişki vardır.

Kariyerinden memnun olan meslek mensuplarının UFRS' nin kavramlarına ve değerleme ölçülerine hâkim olması beklenir. Uyar ve Güngörmüş’ ün (2013) çalışmasında, muhasebe meslek mensuplarının genel UFRS bilgisi ve değerleme ölçüleri ile ilgili bilgi düzeyleri ölçülmüştür. Kariyerinden memnun olan meslek mensuplarının, UFRS bilgi düzeyinin yüksek olması beklenir. 
3. Hipotez: Kariyer memnuniyeti ile UFRS bilgi düzeyi arasında pozitif yönlü ilişki vardır.

\section{ARASTTIRMANIN YÖNTEMI}

$\mathrm{Bu}$ araştırma kapsamında, proaktif kişilik özelliğinin kariyer memnuniyeti üzerine etkisi ve kariyer memnuniyetinin de UFRS' ye bakış açısı ve bilgi düzeyi üzerine olan etkisi araştırılmıştır. Araştırma anket yöntemi ile yapılmıştır. Araştırmanın teorik varsayımları doğrultusunda oluşturulan hipotezler YEM ile modellenmiştir. Verilerin analizinde ve araştırma modelinin test edilmesinde Smart PLS paket programı kullanılmıştır.

\section{a. Araştırma Örneklemi ve Ölçekler}

Araştırmamızda ana kütlenin tamamına ulaşmak mali ve teknik açıdan çok güç olacağından anket çalışması genel istatistiksel olmayan yargısal örnekleme yaklaşımı ile yapılmıştır. Anket, meslek mensuplarının, gruplarının ve meslek odalarının web sayfalarından derlenen e-posta adreslerinden oluşturulan havuzundaki 2.000 meslek mensubuna internet ortamında uygulanmıştır. Anketi 176 meslek mensubu cevaplamış, bir anket analiz dışı bırakılmıştır (Tablo 1). Araştırmada kullanılan modelin yapısal geçerliliğini test etmek için Yapısal eşitlik modeli (YEM) dâhilinde, Löhmoller’ in (1981) Partial Least Squares (PLS) algoritması kısmi en küçük kareler yöntemi kullanılmıştır. Bu yöntemde değişken başına 10 adet anket yeterli olarak kabul edilmektedir. Bizim çalışmamızda dört adet değişken bulunmakta ve anket sayısı bu açıdan yeterli olarak kabul edilebilir sınırlar içerisindedir.

Araştırma verilerinin toplanmasında kullanılan anket formu 5 bölümden oluşmaktadır. Ankette verilen ifadelerin desteklenme dereceleri 5' li likert ölçeği kullanılarak ölçülmüştür. Ölçeklerde yer alan ' 1 ' sayısı "Hiçbir zaman” veya "Kesinlikle katılmıyorum” ve '5' sayısı "Her zaman” veya "Tamamen katılıyorum” seçeneklerini ifade etmektedir. Birinci bölümde proaktif kişilik özelliklerini değerlendiren 8 adet ifade, Bateman, T.S. \& J.M. Crant (1993) tarafından geliştirilen çalışmadan ( $\alpha=0,85)$ alınmıştır (Şahbazoğlu, M., 2014). İkinci bölümde kariyer memnuniyetini değerlendiren 5 adet ifade, Greenhaus, Parasuraman ve Wormley (1990) ve Hofmans vd., (2008) tarafından geliştirilen çalışmadan $(\alpha=0,74)$ alınmıştır (Avcı ve Turunç, 2012; Aktaş H., 2014). Üçüncü bölümde UFRS’ ye bakış açısı, Hatipoğlu, O. (2009) çalışmasının "uygulanabilirlik beklentisi” kısmındaki 6 adet ifadeden alınmıştır.

Dördüncü bölümde bilgi düzeyi ölçeği tarafımızdan geliştirilmiştir. Bu bölümde 7 adet UFRS’ ye özgü değerleme ölçüsü sorulmuştur. Bu ölçekte de likert ölçeği kullanılarak, bilgi düzeyleri '1' sayısı "Hiç bilmiyorum" ve '5' sayısı "Çok iyi biliyorum" aralığında ölçülmüştür. Bilgi düzeyi ölçeğinde yer alan değerleme ölçüleri, "Gerçeğe uygun değer", "Geri kazanılabilir değer”, "İtfa edilmiş maliyet”, “Kalıntı değer”, “Kullanım değeri”, "Net gerçekleşebilir değer" ve "Yerine koyma maliyeti” şeklindedir.

Araştırmaya katılanların demografik özellikleri Tablo 1' de gösterilmiştir. 
Tablo 1: Katılımcıların Demografik Özellikleri (N=175)

\begin{tabular}{|c|c|c|c|}
\hline & Değiş̧kenler & Frekans & \% (Yüzde) \\
\hline \multirow[t]{3}{*}{ Cinsiyet } & Kadın & 20 & 11,4 \\
\hline & Erkek & 155 & 88,6 \\
\hline & Toplam & 175 & 100,0 \\
\hline \multirow[t]{6}{*}{ Yaş } & $<30$ & 17 & 9,7 \\
\hline & $31-40$ & 76 & 43,4 \\
\hline & $41-50$ & 51 & 29,1 \\
\hline & $51-60$ & 23 & 13,1 \\
\hline & $>60$ & 8 & 4,6 \\
\hline & Toplam & 175 & 100,0 \\
\hline \multirow[t]{6}{*}{ Eğitim Durumu } & Lise & 5 & 2,9 \\
\hline & Ön lisans & 3 & 1,7 \\
\hline & Lisans & 118 & 67,4 \\
\hline & Yüksek lisans & 45 & 25,7 \\
\hline & Doktora & 4 & 2,3 \\
\hline & Toplam & 175 & 100,0 \\
\hline \multirow[t]{6}{*}{\begin{tabular}{|l|} 
Mesleki Tecrübe(Yil) \\
\end{tabular}} & $1-5$ & 20 & 11,4 \\
\hline & $6-10$ & 25 & 14,3 \\
\hline & $11-15$ & 38 & 21,7 \\
\hline & $16-20$ & 40 & 22,9 \\
\hline & $>20$ & 52 & 29,7 \\
\hline & Toplam & 175 & 100,0 \\
\hline \multirow[t]{7}{*}{ Çalışma Şekli } & Kendime ait SMMM bürosu & 62 & 35,4 \\
\hline & Kendime ait YMM- DENETIM bürosu & 14 & 8,0 \\
\hline & DENETIM firmasında personel & 7 & 4,0 \\
\hline & SMMM bürosunda personel & 10 & 5,7 \\
\hline & Özel bir firmada personel & 77 & 44,0 \\
\hline & Diğer & 5 & 2,9 \\
\hline & Toplam & 175 & 100,0 \\
\hline \multirow[t]{6}{*}{ Unvan } & Mali işler müdürü & 62 & 35,4 \\
\hline & Muhasebe müdürü & 40 & 22,9 \\
\hline & Muhasebe müdür yardımcısı & 13 & 7,4 \\
\hline & Muhasebe elemanı & 25 & 14,3 \\
\hline & Diğer & 35 & 20,0 \\
\hline & Toplam & 175 & 100,0 \\
\hline \multirow[t]{6}{*}{ Aylık Gelir (TL) } & $\leq 2.000$ & 13 & 35,4 \\
\hline & $2.001-4.000$ & 82 & 22,9 \\
\hline & $4.001-6.000$ & 29 & 7,4 \\
\hline & $6.001-10.000$ & 31 & 14,3 \\
\hline & $\geq 10.001$ & 20 & 20,0 \\
\hline & Toplam & 175 & 100,0 \\
\hline
\end{tabular}




\section{b. Araştırmanın Modeli}

Araştırmanın modeli, kavramsal çerçeve dâhilinde ortaya konan araştırma hipotezleri doğrultusunda oluşturulmuştur. Şekil 1' de araştırmanın teorik modeli gösterilmiştir.

Şekil 1: Araştırmanın Teorik Modeli

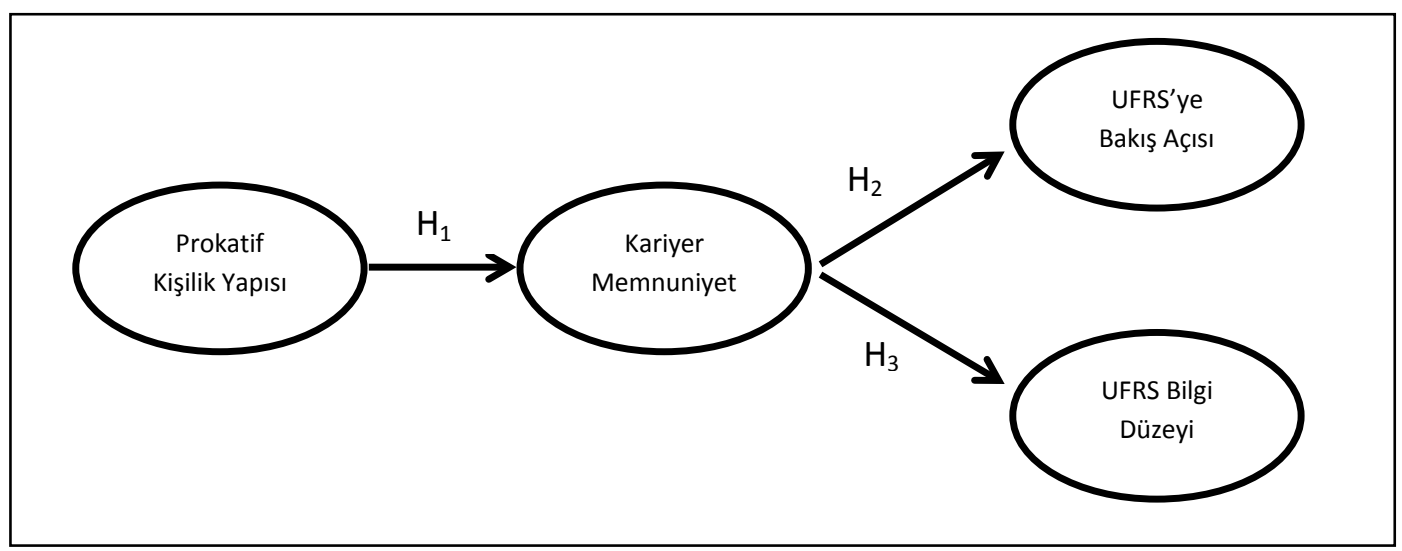

Modelde yer alan değişkenler arasında öngörülen ilişkilerin test edilmesinde nedensellik modeli (Casual Research Model) kullanılmıştır (Kohler, 1994).

\section{VERİ ANALIZİ VE BULGULAR}

Araştırmada modelin yapısal geçerliliğini (YEM) test etmek için, kısmi en küçük kareler yöntemi (PLS= Partial Least Squares) kullanılmıştır. $\mathrm{Bu}$ yöntemle modeldeki değişkenlerin geçerlilik ve güvenirlilik analizleri yapılmıştır. Gizli değişkenlerle (latent variables), gözlemlenebilen değişkenler (manifest variables) arasındaki ilişkileri temsil eden model ve bu çerçevede oluşturulan hipotezler test edilmiştir (Hair vd., 1998). Bu yöntem, normal dağılıma uygun olmayan verilerin kullanılabilmesine olanaklı kılması ve görece küçük örneklem sayısının bulunması nedeniyle tercih edilmiştir (Chin, 1998; Barclay vd., 1995). Yöntemin, çalışmadaki değişkenlerin ölçülebilmesini sağlayacağı düşünülmüş ve Smart PLS 2.0 M3 (Ringle vd., 2005) programı kullanılarak, toplanan veriler araştırma modeli doğrultusunda analiz edilmiştir.

\section{a. Güvenilirlik ve Geçerlilik}

Modeldeki değişkenlerin geçerliliğini ölçmek için muhasebe meslek mensuplarından toplanan verilere doğrulayıcı faktör analizi (DFA) yapılmıştır. DFA ile modeldeki değişkenlerin yakınsak geçerlilikleri (convergent validity) ölçülmüştür. Faktör yükleri, bütünleşik güvenirlilik (CR) (composite reliability), açıklanan ortalama varyans (AOV) değerleri yakınsak geçerliliğini doğrulamaktadır.

Modelin testinde faktör yükleri, bütünleşik güvenirliliği, açıklanan ortalama varyans, yakınsak geçerlilikleri ve ayırt edici geçerlilik değerleri kullanılmıştır. Kısaca modelin güvenirliliği ve içsel tutarlığı test edilmiştir. Tablo 2' de açıklanan ortalama varyans, bütünleşik güvenirlik ve değişkenlerin güvenirlik katsayıları (cronbach’s alpha) gösterilmiştir. Sonuçlar kabul edilebilen ya da kabul değerlerinin daha üzerinde çıkmıştır. AOV skorları 0,56 
ile 0,88 arasındadır. Bu değerler kabul edilen 0,50 değerinin üzerindedir (Fornell ve Larcker, 1981). Bütünleşik güvenirlilik değerleri 0,80 ile 0,94 arasındadır ve önerilen 0,70 değerinin üstünde olduğu görülmektedir (Nunnally, 1978). Cronbach's alpha güvenirlilik değerleri ise tavsiye edilen 0,70 değerinin üstündedir. Proaktif kişilik değişkenin $\alpha=0,62$ olmakla birlikte, $\operatorname{AOV}(0,56)$ ve bütünleşik güvenilirlik değeri $(0,80)$ kabul değerlerinin üzerinde olduğundan, bu değer kabul edilmiştir. Bu verilere göre, modelin güvenirlik ve içsel tutarlık kriterlerini karşıladığı söylenebilir.

Şekil 2: Önerilen Modelin İstatistikî Değerlerle Gösterimi

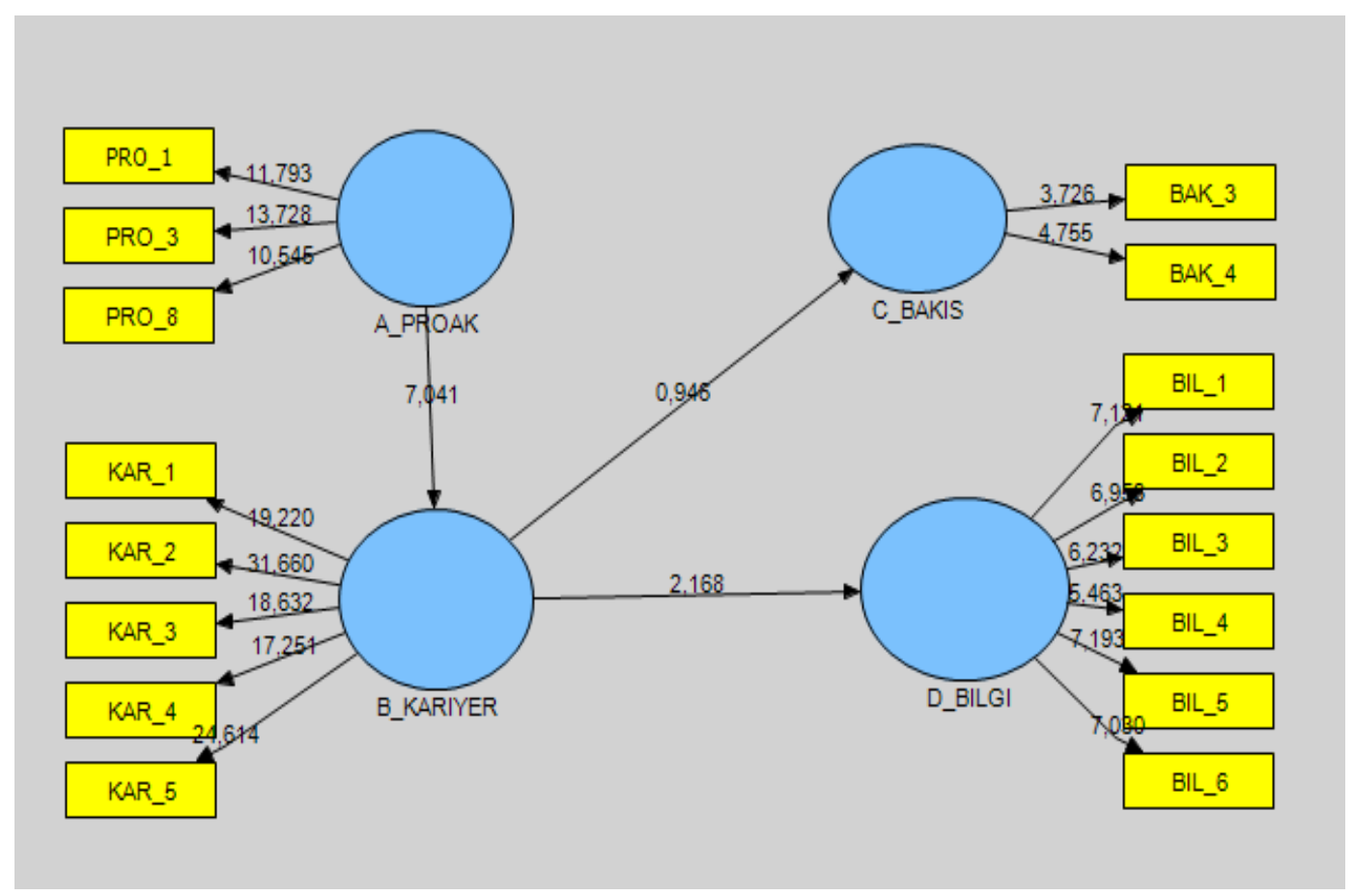

Tablo 2: Yakınsak Geçerlilik Değerleri

\begin{tabular}{lcccc}
\hline $\begin{array}{l}\text { Gizli } \\
\text { değişkenler }\end{array}$ & $\begin{array}{c}\text { Açılkanan } \\
\text { Ortalama } \\
\text { Varyans }\end{array}$ & $\begin{array}{c}\text { Bütünleşik } \\
\text { Güvenilirlik }\end{array}$ & $\begin{array}{c}\text { Cronbach’s } \\
\text { Alpha }\end{array}$ & R-Kare \\
\hline Proaktif K. & 0,564 & 0,795 & 0,617 & \\
Kariyer M. & 0,647 & 0,902 & 0,865 & 0,126 \\
Bakış A. & 0,883 & 0,938 & 0,871 & 0,007 \\
Bilgi D. & 0,708 & 0,936 & 0,917 & 0,022 \\
\hline
\end{tabular}

Faktör yükleri gözlenen değişkenlerle gizli değişkenlerin arasındaki ilişkiyi ifade eden değerlerdir. Tablo 2' de gözlenebilir değişsenlerin faktör yükleri ile yapı arasındaki ilişkiler verilmiştir. Çalışmada elde edilen değerler tavsiye edilen eşik değeri 0,50' den yüksektir (Hair vd., 1998). Bu da gözlemlenebilen değişkenlerdeki değişimin, gizli değişkendeki değişimi açıklayıcı özeliğinin göstergesidir. 
Tablo 3' de bulunan yüklerin hepsi 0,70 değerinden büyük olan değerlerdir. Dolayısıyla genel olarak modelin yakınsak geçerlilik koşullarını sağladığını ifade edebiliriz. 0,70’ nin altında kalan değişkenler analize dâhil edilmemiştir.

Tablo 3: Faktör Yükleri

\begin{tabular}{|l|c|c|c|c|}
\hline & Proaktif $\boldsymbol{K}$. & Kariyer $\boldsymbol{M}$. & Bakı̧ A. & Bilgi D. \\
\hline BIL_1 & 0,028 & 0,139 & 0,228 & $\mathbf{0 , 8 4 4}$ \\
\hline BIL_2 & 0,051 & 0,157 & 0,279 & $\mathbf{0 , 8 6 8}$ \\
\hline BIL_3 & 0,122 & 0,161 & 0,205 & $\mathbf{0 , 8 3 8}$ \\
\hline BIL_4 & $-0,034$ & 0,130 & 0,160 & $\mathbf{0 , 7 9 4}$ \\
\hline BIL_5 & 0,129 & 0,177 & 0,163 & $\mathbf{0 , 8 7 3}$ \\
\hline BIL_6 & 0,058 & 0,131 & 0,221 & $\mathbf{0 , 8 2 7}$ \\
\hline BAK_3 & $-0,039$ & 0,094 & $\mathbf{0 , 9 5 7}$ & 0,230 \\
\hline BAK_4 & $-0,044$ & 0,071 & $\mathbf{0 , 9 2 3}$ & 0,238 \\
\hline KAR_1 & 0,402 & $\mathbf{0 , 8 0 5}$ & 0,133 & 0,172 \\
\hline KAR_2 & 0,401 & $\mathbf{0 , 8 5 7}$ & 0,130 & 0,171 \\
\hline KAR_3 & 0,354 & $\mathbf{0 , 7 7 1}$ & 0,008 & 0,037 \\
\hline KAR_4 & 0,239 & $\mathbf{0 , 7 6 4}$ & 0,045 & 0,188 \\
\hline KAR_5 & 0,370 & $\mathbf{0 , 8 2 2}$ & 0,012 & 0,143 \\
\hline PRO_1 & $\mathbf{0 , 7 5 5}$ & 0,286 & $-0,097$ & 0,038 \\
\hline PRO_3 & $\mathbf{0 , 7 5 6}$ & 0,357 & $-0,026$ & 0,046 \\
\hline PRO_8 & $\mathbf{0 , 7 4 3}$ & 0,355 & 0,012 & 0,085 \\
\hline
\end{tabular}

Tablo 4: Ayırdedici Geçerlilik (Discriminant) Testi. Değişkenlerin Korelâsyonları ve AOV Karekök Değerleri

\begin{tabular}{l|cccc}
\hline Değişkenler & $\mathbf{1}$ & $\mathbf{2}$ & $\mathbf{3}$ & $\mathbf{4}$ \\
\hline 1 Proaktif K. & $\mathbf{0 , 7 5 1}$ & & & \\
$\mathbf{2}$ Kariyer M. & 0,448 & $\mathbf{0 , 8 0 5}$ & & \\
3 Bakış A. & $-0,044$ & 0,090 & $\mathbf{0 , 9 4 0}$ & \\
4 Bilgi D. & 0,076 & 0,179 & 0,248 & $\mathbf{0 , 8 4 1}$ \\
\hline
\end{tabular}

Ayırt edici (discriminant) analizi ile modeli oluşturan her değişken ayrı olarak analiz edilmiştir. Bu analizle modelde kullanılan her değişkenin AOV' sının karekök değerleri diğer değişkenlerin korelâsyonları ile karşılaştırılmıştır. Burada AOV karekök değerleri diğer değişkenlerin korelâsyonlarından daha büyük olması tavsiye edilmektedir (Chin, 1998). Değişkenlerin birbirleriyle korelâsyonları ve AOV karekök değerleri koyu renkli olarak Tablo 3’ de gösterilmiştir. Elde edilen bulgulara göre matrisin ana köşegen dışındaki sonuçları (değişkenlerin korelâsyonları) ana köşegen değerlerinden (AOV karekök değerleri) az ya da eşit olması gerekmektedir. $\mathrm{Bu}$ nedenle ayırt edici geçerliliğinde bir sorun olmadığı görülmektedir. Dolayısıyla önerilen model geçerli ve güvenilirdir. 


\section{b. Analiz Sonuçları}

Tablo 2' de gizli bağımlı değişkenlerin bağımsız değişkenlerce ne ölçüde açıklandığı gösterilmiştir. Buna göre, kariyer memnuniyeti açısına ait genel görüşlerin \%12,6, UFRS bakış açısına ait genel görüşlerin \% $0,7^{\prime}$ si ve UFRS bilgi düzeyine yönelik görüşün $\% 2,2$ ' sinin bağımsız değişkenler tarafından açıkladığı görülmüştür.

Model daha önce de ifade edildiği gibi YEM ile analiz edilmiştir. Bu analizde $\mathrm{R}^{2}$ ve yol değerleri için elde edilen istatistik değerlerden anlamlı olanlar kullanılmaktadır. $\mathrm{Bu}$ çerçevede gizli değişkenler arasındaki anlamlı istatistiksel değerler ele alınmakta ve sonuç çıkartılmaktadır. PLS yöntemi kullanılırken araştırmada bootstrapping yöntemi (örneklemi yeniden hesaplama yöntemi/ önyükleme yöntemi) kullanılarak 500’ e çıkartılmıştır.

\section{Hipotez: Proaktif kişilik ile Kariyer memnuniyeti arasında pozitif yönlü ilişki} vardır.

Yapılan analizde, proaktif kişilik özelliklerine sahip olan muhasebe meslek mensuplarının kariyer memnuniyetleri arasında pozitif yönde bir ilişki tespit edilmiştir. Ortaya çıkan pozitif ilişki ile proaktif kişilik yapısına sahip olan muhasebe meslek mensuplarının kariyerlerinden memnun oldukları görülmüştür. Bu ilişki $\mathrm{p}<0,01$ düzeyinde ve $\beta=0,44$ yol katsayısı istatistikî olarak yükssek anlamlı çıkmıştır. Hipotez 1 kabul edilmiştir.

2. Hipotez: Kariyer memnuniyeti ile UFRS' ye olumlu bakış açısı arasında pozitif yönlü ilişki vardır.

Yapılan analizde kariyerinden memnun olan muhasebe meslek mensuplarının UFRS' ye bakışına yönelik pozitif yönde bir ilişki tespit edilememiştir. Hipotez 2 reddedilmiştir.

\section{Hipotez: Kariyer memnuniyeti ile UFRS bilgi düzeyi arasında pozitif yönlü ilişki} vardir.

Yapılan analizde kariyerinden memnun olan muhasebe meslek mensuplarının UFRS değerleme ölçülerine yönelik bilgi düzeyleri arasında pozitif yönde bir ilişki tespit edilmiştir. Ortaya çıkan pozitif ilişki ile kariyer memnuniyeti yüksek olan muhasebe meslek mensuplarının, UFRS değerleme ölçülerini bilme düzeylerinin yüksek olduğu görülmüştür. $\mathrm{Bu}$ ilişki $\mathrm{p}<0,05$ düzeyinde ve $\beta=0,17$ yol katsayısı istatistikî olarak anlamlı çıkmıştır. Hipotez 3 kabul edilmiştir.

Tablo 5: Özet Olarak Test Sonuçları

\begin{tabular}{|c|c|c|c|c|c|}
\hline \multicolumn{3}{|c|}{ Hipotezsel İlişkiler } & \multirow{2}{*}{$\frac{\text { ק Katsayılar }}{0,448}$} & \multirow{2}{*}{$\frac{\text { T Değerleri }}{7,041}$} & \multirow{2}{*}{$\begin{array}{l}\text { Sonuçlar } \\
* * * \text { Destekliyor }\end{array}$} \\
\hline Proaktif K. & $\rightarrow$ & Kariyer M. & & & \\
\hline Kariyer M. & $\rightarrow$ & Bakış A. & 0,090 & 0,946 & Desteklemiyor \\
\hline Kariyer M. & $\rightarrow$ & Bilgi D. & 0,179 & 2,168 & **Destekliyor \\
\hline
\end{tabular}




\section{SONUÇ}

Araştırmamızda, dış etkenlerden kolay etkilenmeyen, inisiyatif alabilen, hedefleri olan ve sonuç odaklı çalışan proaktif kişilik özelliklerine sahip muhasebe meslek mensuplarının kariyer memnuniyetlerinin daha yüksek düzeyde olduğu görülmüştür.

Yapılan analizde kariyerinden memnun olan muhasebe meslek mensuplarının UFRS nin muhasebe mesleğinin gelişimine olumlu katkı sağlayarak, şeffaflığı artıracağı, ülkenin ekonomik yapısı ile uyumlu olarak iş dünyasına olumlu katkı sağlayacağı noktasında anlamlı bir ilişki tespit edilememiştir. $\mathrm{Bu}$ durum muhasebe meslek mensuplarının UFRS' nin uygulanması ile ilgili geleceğe yönelik görüşlerinde bir netlik olmadığı şeklinde yorumlanabilir.

Kariyerinden memnun olan muhasebe meslek mensuplarının UFRS değerleme ölçülerine yönelik bilgi düzeyleri arasında pozitif yönde bir ilişki tespit edilmiştir. Ortaya çıkan pozitif ilişki ile kariyer memnuniyeti yüksek olan muhasebe meslek mensuplarının UFRS değerleme ölçülerini bilme düzeylerinin yüksek olduğu görülmüştür. Bu sonuç proaktif kişilik yapısı ile örtüşmektedir. Proaktif kişilik yapısına sahip bireyler, iş hayatındaki hedeflere ulaşmak için sürekli kendilerini geliştirir ve bu yönde caba içinde olurlar.

Kariyer memnuniyeti yüksek meslek mensuplarının UFRS bilgi düzeylerinin iyi olmasına rağmen, UFRS bakış açılarının net olmaması, UFRS' nin katacağı artı değerler ile ilgili bazı soru işaretleri olduğunu göstermektedir. Bu belirsizliğin nedenleri arasında, UFRS' ye geçiş sürecinin uzaması, yasal düzenlemelerin tamamlanmamış olması, finans sektörünün desteğinin zayıf olması, şirketlere ve muhasebe mesleğine getireceği artı değerin tam anlaşılamamış olması gibi faktörler sayılabilir. Bu bağlamda, yasal düzenlemelerin hızlı bir şekilde tamamlanması, meslek odalarının bilgi düzeyini arttırıcı eğitimlerin yanında, UFRS' nin şirketlere ve meslek mensuplarına katkılarına yönelik konferans ve seminerler ile bilgilendirme yapmaları belirsizliğin ortadan kaldırılmasına katkı sağlayacaktır.

\section{KAYNAKLAR}

Ağca, Ahmet - Dalkılıç, Elçin (2014), “Muhasebe meslek mensupları Kobi' ler için TFRS' ye hazır mı?”, Dumlupınar Üniversitesi Sosyal Bilimler Dergisi, 39, ss. 1-19.

Aktaş, Hakkı (2014), "Kariyer Safhaları ile Demografik Değişkenler Bağlamında Kariyer Memnuniyeti ve Mesleki Bağlılık İlişkisi: Büra Yöneticileri, Yönetici Asistanları ve Sekreterler Üzerinde Bir Araştırma”, International Journal of Social Science, 26, ss. 195-212.

Ashford, Susan J. - Black, J. Stewart (1996), “Proactivity During Organizational Entry: The Role Of Desire For Control”, Journal of Applied Psychology, 81, pp. 199-214.

Avcı, Umut - Turunç, Ömer (2012), "Dönüşümcü Liderlik ve Örgüte Güvenin Kariyer Memnuniyetine Etkisi: Lider-Üye Etkileşiminin Aracılık Rolü”, Uluslararası Alanya İşletme Fakültesi Dergisi, 4(2), ss. 45-55. 
Ballas, A. Apostolos - Skoutela, Despina - Tzovas, A. Christos (2010), "The Relevance of IFRS to an Emerging Market: Evidence from Greece”, Managerial Finance, 36(11), pp.931-948.

Barcla, Donald - Higgins, Christopher - Thompson, Ron (1995). “The Partial Least Squares (PLS) Approach to Causal Modeling: Personal Computer Adoption and Use as an Illustration”, Technology Studies, 2(2), pp. 285-309.

Bateman, S. Thomas - Crant, J. Michael (1993), “The Proactive Component Of Organizational Behavior”, Journal of Organizational Behavior, 14, pp.103-118.

Bell, E. Nancy - Staw, M. Barry (1989), "People as Sculptors Versus Sculpture: The Role Of Personality And Personal Control İn Organizations”, Arthur, B. Michael - Hall, T. Douglas - Lawrence, S. Barbara (Ed.), The Handbook of Career Theory, Cambridge, Cambridge University Press, pp. 232-251,

Bengü, Haluk - Özdemir, Fevzi Serkan - Çelik, Serpil (2014), "Niğde İlindeki Muhasebe Meslek Mensuplarının Finansal Raporlama Standartlarına Bakış Açılarının Ampirik Olarak Değerlendirilmesi”, Niğde Üniversitesi İIBF Dergisi, 7(1), ss. 161-175.

Chin, W. Wynne (1998), "Issue and Opinions on Structural Equation Models with Unobservable Variables and Measurement Error”, Journal of Marketing Research, 18, s. 39-50.

Crant, J. Michael (1995), “The Proactive Personality Scale And Objective Job Performance Among Real Estate Agents”, Journal of Applied Psychology, 80, pp.532-537.

Fornell, Claes - Larcker, F. David (1981), "Evaluating Structural Equation Models with Unobservable Variables and Measurement Error”, Journal of Marketing Research, 18(1), pp. 39-50.

Frese, Michael - Fay, Doris - Hilburger, Tanj. - Leng, Karena - Tag, Almut (1997), “The Concept Of Personal İnitiative: Operationalization, Reliability and Validity in two German Samples”, Journal of Occupational and Organizational Psychology, 70, pp. 139-161.

Greenhaus, H. Jeffrey - Parasuraman, Saroj - Wormley, M. Wayne (1990), “Effects of Race On Organizational Experiences, Job Performance Evaluations, and Career Outcomes”, Academy of Management Journal, 33, pp. 64-86.

Hair, F. Joseph - Ralph, E. Anderson - Ronald, L. Tatham - William C. Black (1998), Multivariate Data Analysis, 5. ed. Upper Saddle River, Prentice Hall, New Jersey.

Hatipoğlu, Oğuzhan (2009), “Türkiye’ de Uluslararası Muhasebe Standartları’ nın Gelişimi, Gerekliliği ve Uygulanabilirliği Üzerine Bir Araştırma”, Karadeniz Teknik Üniversitesi SBE, Yayınlanmamış Yüksek Lisans Tezi, Trabzon. 
Hatunoğlu, Zeynep - Uçaktürk, Mahmut - Kılll, Mustafa (2013), “Türkiye Finansal Raporlama Standartları' nın bilinilirlik düzeyi üzerine Kahramanmaraş’ ta bir alan çalışması", Niğde Üniversitesi İ̈BF Dergisi, 6(1), ss. 51-62.

Hofmans, Joeri - Dries, Nicky - Pepermans, Roland (2008). “The Career Satisfaction Scale: Response Bias among Men and Women”, Journal of Vocational Behavior, 73(3), pp.397-403.

Jones, Stewart - Higgins, D. Alison (2006), “Australia’ s Switch To İnternational Financial Reporting Standars: A Perspective From Account Preparers”, Accounting \& Finance, 46(4), pp.629-652.

Judge, A. Timothy - Bretz, D. Robert (1994), "Political İnfluence Behavior And Career Success”, Journal of Management, 20, s. 43-65.

Judge, A. Timothy - Cable, M. Daniel - Boudreau, W. John - Bretz, D. Robert (1995), “An Empirical İnvestigation Of The Predictors Of Executive Career Success”, Personnel Psychology, 48, pp. 485-519.

Karabınar, Selahattin (2005), Kültür-Muhasebe Etkileşimi Açısından Muhasebe İklimi, Seçkin Yayınları, Ankara.

Kohler, Heinz (1994), Statistics for Business and Economics, Harper Collins Publishers, New York.

Larson, K. Robert - Street, L. Donna (2004), "Convergence with IFRS in an Expanding Europe: Progress and Obstacles Identified by Large Accounting Firms' Survey”, Journal of International Accounting Auditing and Taxation, 13(2), pp. 89-119.

Nunnally, C. Jum (1978), Psychometric Methods, McGraw Hill, New York.

Seibert, E. Scott - Crant, J. Michael - Kraimer L. Maria (1999), "Proactive Personality and Career Success”, Journal of Applied Pcychology, 84, 3, pp. 416-427.

Şahbazoğlu, Meltem (2014), “The Relationship between Proactive Personality, Empowerment and Proactive Work Behavior", Yeditepe Üniversitesi SBE, Yayınlanmamış Doktora Tezi, İstanbul.

Tyrrall, David - Woodward, David - Rakhimbekova, Almagoul (2007), “The Relevance of International Financial Reporting Standards to a Developing Country: Evidence from Kazakhstan”, The International Journal of Accounting, 42(1), pp.82-110.

Uyar, Ali - Güngörmüş, Ali Haydar (2013), "Perceptions and Knowledge Of Accounting Professionals on IFRS for SMEs: Evidence from Turkey”, Research in Accounting Regulation, 25, ss.77-87.

Wayne, J. Sandy - Liden, C. Robert - Kraimer, L. Maria - Graf, K. Isabel (1999), “The Role Of Human Capital, Motivation And Supervisor Sponsorship İn Predicting Career Success”, Journal of Organizational Behavior, 20 (5), pp. 577-595 